\title{
New NSLP Guidelines: Challenges and Opportunities for Nutrition Education Practitioners and Researchers
}

\section{Authors: Carmen Byker Shanks, Courtney A. Pinard, Amy L. Yaroch, Elena L. Serrano}

NOTICE: this is the author's version of a work that was accepted for publication in Journal of Nutrition Education and Behavior. Changes resulting from the publishing process, such as peer review, editing, corrections, structural formatting, and other quality control mechanisms may not be reflected in this document. Changes may have been made to this work since it was submitted for publication. A definitive version was subsequently published in Journal of Nutrition Education and Behavior, [VOL\# 45, ISSUE\# 6, (November 2011)] DOI\# 10.1016/j.jneb.2013.06.004

Byker, Carmen J., Courtney A. Pinard, Amy L. Yaroch, and Elena L. Serrano. "New NSLP Guidelines: Challenges and Opportunities for Nutrition Education Practitioners and Researchers." Journal of Nutrition Education and Behavior 45, no. 6 (November 2013): 683689. doi:10.1016/j.jneb.2013.06.004.

Made available through Montana State University's ScholarWorks scholarworks.montana.edu 


\title{
New NSLP Guidelines: Challenges and Opportunities for Nutrition Education Practitioners and Researchers
}

\author{
Carmen J. Byker, $\mathrm{PhD}^{1}$; Courtney A. Pinard, $\mathrm{PhD}^{2}$; Amy L. Yaroch, $\mathrm{PhD}^{2}$; Elena L. Serrano, $\mathrm{PhD}^{3}$ \\ 1 Department of Health \& Human Development, Montana State University, Bozeman, MT \\ 2 Gretchen Swanson Center for Nutrition, Omaha, NE \\ 3 Department of Human Nutrition, Foods, and Exercise, Virginia Tech, Blacksburg, VA
}

\begin{abstract}
The recent revisions of the National School Lunch Program (NSLP) requirements are designed to align with the 2010 Dietary Guidelines for Americans. The introduction and implementation of the new NSLP has been received with positive and negative reactions from school food professionals, students, parents, and teachers. To promote student health, this is an important time for policy makers, practitioners, and researchers to implement and evaluate strategies to support the new NSLP guidelines. The purpose of this viewpoint was to outline the new NSLP guidelines and discuss challenges and opportunities for implementation, strategies for practice, and future research questions.

Key Words: National School Lunch Program, nutrition standards, schools (J Nutr Educ Behav. 2013;45:683-689.)
\end{abstract}

\section{INTRODUCTION}

The United States Department of Agriculture (USDA) established the National School Lunch Program (NSLP) in $1946 .^{1}$ The NSLP is a federally funded program that currently serves more than 30 million students each day in over 100,000 schools in the US. ${ }^{1}$ Quality nutrition in the NSLP program is important given that NSLP participants consume approximately $40 \%$ of their actual caloric intake at lunch, which is higher than non-NSLP participants. ${ }^{2}$ In 2010, the Healthy Hunger-Free Kids $\mathrm{Act}^{3}$ required updating the meal patterns and nutrition standards for the NSLP and the School Breakfast Program (SBP). The new guidelines align with the 2010 Dietary Guidelines for Americans (DGA) ${ }^{4}$ to “... meet the nutrition needs of school children" and "enhance the diet and health of school children, and help mitigate the childhood obesity trend. quired to be implemented beginning July 1, 2012 and Fall, 2012 marked the beginning of implementation for the majority of the components of the new NSLP guidelines across the US. ${ }^{6}$ The purposes of this report were first to describe opportunities and challenges while reviewing the new NSLP standards, and then to discuss suggestions for implementation, promotion of the standards in practice, and future research and evaluation. Implementation of the SBP guidelines will occur over 2 years beginning during the 2013-2014 school year. The NSLP guidelines and their implementation are the focus of this report.

Since the implementation of the new NSLP guidelines, there have been many different reactions expressed by policy makers, school foodservice personnel, parents, students, and others across the country. Iowa Congressman Steve King stated that he planned to repeal the new standards: "They have found a way to invade the lunch tray of the youngest members of our society, what's next? The new regulations are a one-size-fits-all encroachment of our liberties."7 Other states and school districts have demonstrated support for the changes, acknowledging that they may ultimately benefit students and may potentially help in curbing the obesity epidemic. The USDA began to collect feedback from key stakeholders about the new guidelines and have since revised specific components accordingly. ${ }^{8}$ This is a critical time for nutrition education professionals, researchers, and policy makers to assist with the implementation, measurement, and evaluation of such a broad-reaching policy.

This viewpoint outlines the specific standards and strategies for the new NSLP guidelines, along with recommendations for overcoming challenges found in implementation, promotion of the standards in practice, and future research and evaluation.

\section{National School Lunch Program Standards}

The Food and Nutrition Service of the USDA regularly updates regulations and policy memos, and provides tech-nical assistance and guidance mate-rials about the new NSLP guidelines, including specific nutrient require-ments. ${ }^{9}$ Below, the specific standards implemented during the 2012-2013 
academic year are summarized by food group, ${ }^{6}$ with successes and challenges in implementation highlighted.

\section{Approaches to Menu Planning and Serving}

School food authorities (SFAs) are responsible for administering school feeding programs. ${ }^{10}$ School food authorities must serve meals that offer 5 meal components daily, including fruits, vegetables, grains, meat/meat alternate, and milk. The serving sizes within the 5 meal components are planned based on kindergarten through 5, 6-8, and 9-12 age/grade groups. There is some overlap of nutrient requirements within the kindergarten through 8 age/grade groups that offers ease in menu planning for schools with combined age/grade levels. In addition, offer vs serve (OVS) now allows students to decline 2 food items, but students must choose $1 / 2$ cup fruit or vegetable (FV) or $1 / 4$ cup fruit and $1 / 4$ cup vegetable. Offer vs serve is mandatory for high schools and elective for elementary and middle schools. Offer vs serve provides flexibility for students to choose among preferred meal components and has the potential to reduce food waste.

\section{Calories}

School food authorities are required to formulate meals with minimum and maximum ranges of calories based on age group, whereas previously only minimum calories were required. Reducing calories affects virtually every other area of the new requirements. Minimum serving sizes for the grains and meat/meat alternate components were reduced, whereas the FV components increased, and the milk component remained the same. Some SFAs are finding that implementing the calorie component has not changed their meals drastically, whereas other SFAs find the decrease challenging. ${ }^{11}$ For example, this change could be more noticeable for SFAs that were serving well above the minimum nutrient requirement specified in the previous standards. Like other food components in the new requirements, the calorie require- ments align with the $2010 \mathrm{DGA}^{4}$ and are designed to limit overconsumption. The new requirements were specifically designed to promote quality nutrients and limit excess calories. Promoting energy balance during lunch is a way to reduce childhood obesity. ${ }^{12,13}$

For students accustomed to eating larger portions, however, this could be a marked shift. ${ }^{11}$ The calorie requirements may pose potential challenges for students with higher energy needs. Students may reach energy needs with nutrient-dense options such a salad bars or second servings of FVs without additional lunch charge. ${ }^{11}$ Students with freedom to travel off campus during the lunch hour may choose to eat lunch at other food outlets, potentially of lower nutrient quality. Students with access to vending machines or school stores may also choose to supplement or substitute school lunch with more energy-dense foods. If outside foods and competitive foods are standard alternates or additions to lunch, students using free or reduced may feel stigmatized owing to affordability of other foods.

\section{Fruits and Vegetables}

According to the new requirements, FVs are offered as 2 separate meal components, instead of the previous requirement to offer a fruit or vegetable. The previous requirements only mandated SFAs to offer a fruit or vegetable, with no guidance on the type of vegetable or stipulation that a student had to be served a fruit or vegetable. The goal of this new guideline is to increase exposure to and availability of a variety of FVs, currently addressing a major dietary shortfall as exemplified by the low percentage of children and adolescents meeting recommendations for daily FV consumption. ${ }^{14}$

The new requirements mandate that students must select at least a $1 / 2$ cup of fruit or vegetable or a combination of $1 / 4$ cup fruit and $1 / 4$ cup vegetable under OVS. This OVS caveat is designed to reduce food waste and costs. ${ }^{5}$ The FV guidelines do not mandate that students select both FVs, which would be more optimal for meeting 2010 DGA recommendations, ${ }^{4}$ but could potentially increase food waste.
School food authorities are required to increase the variety of vegetables served during a week period, with weekly requirements for dark green, red/orange, beans/peas (legumes), starches, and other vegetables, as defined in the 2010 DGA, ${ }^{4}$ whereas previously there was no requirement for the type of vegetables served. The requirement has potential to increase the variety of vegetables to which students are exposed, although foodservice personnel may need training and additional equipment to improve cooking preparation knowledge, skills, and capacity to prepare recipes that are appealing to children, while aligning with calorie limits. The vegetable requirement also continues to allow tomato sauce to be counted as a vegetable on pizza, and french fries to be served in limited amounts per week.

The new guidelines allow up to half of the fruit requirement to be met with $100 \%$ fruit juice, even though it provides more calories than whole fruit and is not nutritionally equivalent. One financial issue that is raised is the waste that occurs because increased availability of FVs does not necessarily equate with consumption, especially if students do not demonstrate a preference for FVs. ${ }^{15}$ Although language to promote sourcing for local FVs in schools is included in the Healthy Hunger-Free Kids Act, ${ }^{3}$ the new guidelines may limit local sources because of the potential added costs of offering both FVs and, depending on location, a lack of variety of local produce to meet the variety standards. Overall, the new guidelines help convey the key MyPlate message to "make half your plate fruits and vegetables."16

\section{Meat or Meat Alternate}

In the new ruling, SFAs were originally required to comply with the daily and weekly minimum and maximum ranges of meat and meat alternates, whereas previously there was no weekly maximum. Serving age-appropriate portion sizes are an important step for the NSLP in meeting 2010 DGA, ${ }^{4}$ but again, they face several constraints. The USDA Food and Nutrition Service received much feedback from SFAs about the operational challenges to meet serving size 
requirements. ${ }^{17}$ Currently, some suppliers do not have suitable products for the new requirements, which creates challenges in meeting weekly minimums and maximums for SFAs, $^{17}$ but suppliers will likely respond to the needs of the NLSP. Ultimately, improvements in the food supply chain to meet the new NSLP requirements will align foods being sold in schools with the 2010 DGA. ${ }^{4,18}$ Adjustments to the rule may be made again in the future as more data about implementation are gathered and as suppliers reformulate meat and meat alternate products to match serving size and calorie requirements.

In addition to serving size specifications, tofu and beans/peas (legumes), when not credited as a vegetable, count as a meat alternative. This recommendation offers a new opportunity to introduce more nonmeat proteins into school lunch menus, exposing students to a wider variety of foods and nutrients. Serving less meat and more meat alternatives has potential for improving environmental health and increasing food system sustainability. ${ }^{19}$ Given that meat alternatives were previously allowed, it is questionable whether schools will begin using more meat alternatives beyond the already existing alternatives, such as peanut butter (and jelly) sandwiches (which are restricted in some school divisions because of severe food allergies), given established norms. School food authorities may not have the cooking knowledge, skills, food preparation time, or financial abilities to serve tofu and other soy products in a way that is appetizing to a schoolchild.

\section{Grains}

Under the new rule, SFAs were originally required to comply with the daily and weekly minimum and maximum ranges of grains, whereas previously there was no maximum. The USDA changed this rule after receiving feedback about the challenges SFAs encountered when planning meals. ${ }^{17}$ The new rule requires only daily and weekly minimums to be met for grains during the 2012-2013 school year. ${ }^{17}$ School food authorities reported that grains exist in a variety of meal items, and counting and meeting weekly ranges was difficult given limited appropriate product availability from suppliers. Previously, grains typically comprised a large portion of the school lunch meal, filling students up and contributing to satiety. With the new maximum standards, large grain portions could not be served and bread rolls and crackers could not be offered on the side. This requirement potentially led to reports of hunger. The policy is now changed to require that only daily and weekly minimums be met for grains during the 2012-2013 school year. ${ }^{17}$ Adjustments to the rule may be made again in the future as more data about implementation are gathered.

Still, at least half of the grains must be whole grain-rich under the new requirements. The food industry is already reformulating bread products, such as sandwich rolls, to include more whole grains and meet potential serving size requirements. ${ }^{17}$ For those SFAs that serve the same meals to a broad age range (eg, 7-9 years), it may be difficult to meet varying grain serving size amounts for each age group with the same recipes. Nevertheless, the new grain standards help reinforce the 2010 DGA related to balancing calories and consuming fewer foods with refined grains. ${ }^{4}$ They also help reestablish historical norms regarding appropriate portion sizes, which have become inflated in recent years. $^{20}$

\section{Milk}

School food authorities are required to serve 1 cup of fat-free (unflavored or flavored) or 1\% low-fat (unflavored) milk with each meal. Previously, reduced fat and whole milk options were permitted with no flavor restrictions. Banning flavored milk in schools was a controversial issue previous to the implementation of the new school lunch standards. ${ }^{21}$ This is a balanced approach in which these recommendations allow added sugars from flavoring in milk when fat is decreased.

\section{Saturated Fat and Trans Fat}

School food authorities are required to continue serving meals that comprise
$10 \%$ or less saturated fat of the total meal and 0 grams trans fat per serving. There is no limit on total fat intake. With research clearly associating trans fat with poor health outcomes, ${ }^{22}$ this requirement could encourage food manufacturers producing food for the NSLP to formulate food products to contain less saturated and no trans fats. Manufacturers and school lunch personnel may also add flavor to foods using herbs and spices or monounsaturated and polyunsaturated fats without adding saturated fats or trans fats. Ultimately, combined with lower fat milk options, this recommendation contributes to a heart-healthy diet, related to preventing onset of chronic disease. ${ }^{4}$

\section{Additional Foods}

School food authorities are only allowed to serve FVs as seconds at no cost to the student. School food authorities may serve additional foods other than FVs as à la carte at full price, including entrée seconds (eg, meats and grains) and other food items (eg, snacks), which makes additional food outside of FVs more expensive for the student. Competitive foods sold in vending machines, school stores, or fundraisers are another avenue for students to purchase food items outside the NSLP. This creates potential inequities for students who cannot afford à la carte or competitive food options.

The Healthy, Hunger-Free Kids Act requires that all foods sold outside the school meal program and the school campus, and at any time during the school day should be consistent with the DGA. ${ }^{18}$ The proposed rules require SFAs to include foods that emphasize at least 1 of the 5 food components (eg, whole grains, low-fat dairy, fruits, vegetables, or protein) and limit fat, sugar, and sodium; variation for beverage portions and caffeine content according to age group; and flexibility for when the standards apply (eg, not applicable at celebrations or infrequent fundraisers and bake sales). If approved, the standards will go into effect 1 school year after an implementing rule is published, and states and localities will continue to have the ability to propose stronger standards. 


\section{Water}

New to school nutrition standards, clean and potable water must be available in the lunchroom, in line with recommendations to reduce or eliminate sugar-sweetened beverages and other nutrient-poor beverages. In addition to health benefits, water is generally low-cost. Water jets can be easily implemented in schools throughout the US, encouraging students to drink more water. ${ }^{23}$

\section{SUMMARY OF NSLP MENU CHANGES}

The new NSLP guidelines target recommendations based on DGAs. Providing nutritious meals at lunch to students may be 1 step in improving health, especially in relationship to overweight and obesity. The NSLP guidelines focus on providing 5 meal components, including fruits, vegetables, whole grains, low-fat dairy, and proteins. The meal component servings and calories are based on the appropriate size based on age. Other changes include an emphasis on water, continued restrictions in saturated and trans fat, and new sodium content guidelines (beginning implementation in school year 2014-2015). Foods that are sold in addition to lunch (ie, competitive foods, à la carte, and seconds) will be regulated to meet the DGAs during the school day pending public comment.

The revised standards aim to improve the diet and health of schoolchildren. Today's national contro versy about the NSLP guidelines questions the extent to which the federal government should regulate local SFAs in promoting healthier food options through approving or withholding funds. ${ }^{24-26}$ Federal reimbursement depends, as it always has, on whether SFAs meet the NSLP guidelines. Although participation is required to receive federal reimbursement, schools are not mandated to participate in the NSLP.

The National School Lunch Act was approved in 1946 as a measure of national security after acknowledging the need for stable funding to provide nutritionally sound foods for students, to promote health and learning and academic achieve- ment. $^{27}$ When the NSLP was implemented 67 years ago, it established only minimum nutrient requirements, because excess consumption was not a concern. However, childhood and adolescent obesity have continued to rise over the past few decades, ${ }^{28}$ along with associated comorbidities. Thus, establishing maximum requirements is warranted as a measure of national security. ${ }^{27}$ Returning to the original goal of the NSLP, it is important to establish standards that promote students' health, accepting that today's student nutrient needs have changed.

\section{RECOMMENDATIONS FOR IMPLEMENTATION}

Overhauling the NSLP is an enormous task because it has the potential to affect over 30 million students every day. ${ }^{1}$ To formulate policies that immediately work for every SFA is challenging and, as evidenced by this report, is still undergoing adaptations and interpretation. For example, each SFA around the nation may use a different set of resources; they employ school foodservice workers with various levels of food and nutrition knowledge, outfit kitchens with different equipment and foodservice flows (eg, centralized vs decentralized food service), and serve students with varying food preferences. Nutrition educators could have a role in implementing the new NSLP standards by providing education that is tailored to the local SFAs' given resources. This could include offering information about various meal patterns and options that meet the new NSLP requirements based on the foodservice systems that the SFAS has in place.

To help standardize reporting about the implementation of the NSLP guidelines, SFAs are required to document how 1 week of meals meets requirements through a new computerized system. Learning a new form of documentation may present challenges in the reporting process, but there are also opportunities to capture new information that may help streamline implementation for SFAs around the country. Creating mechanisms through this computerized system that document feedback can help improve guideline implementation.
For example, although it is not currently mandated, the authors suggest that consumption along with recipes be measured (by plate waste or other means) and recorded within the computerized system. Plate waste studies have been completed previously, ${ }^{29}$ but none were about the new NSLP guidelines. Nutrition educators could assist with implementing plate waste studies at various times during a school year and work with the schools to develop a database with recipes and recorded consumption. A system such as this would provide SFAs with a catalog for compliant meal components that students will consume.

Also a challenge to implementation for SFAs, it is difficult, although not impossible, to change individual dietary habits, as evidenced by years of work in childhood obesity prevention. ${ }^{30}$ However, foods that students eat can affect how and what they learn. ${ }^{31}$ School lunchtime can be an effective setting for providing instruction and environmental changes to encourage healthier eating patterns. ${ }^{32,33}$ Meals provided to students that are regulated by the federal government and partially paid for with taxes should align with the 2010 DGA and be responsive to the needs of the entire US student population. Today, it is important to consider the disproportionately high numbers of children and adolescents who are obese. ${ }^{28}$ Nutrition professionals can be effective agents in changing the school food environment ${ }^{30}$ by educating SFAs and students about the relationship between school lunch, eating behaviors, and health.

Finally, nutrition educators could work with SFAs to implement strategies that meet the new NSLP standards and promote food system sustainability at the same time. This could include starting farm to school initiatives or implementing approaches to decrease or divert food waste.

\section{RECOMMENDATIONS FOR PRACTICE}

The NSLP standards calculate nutrient needs based on the average child in an age/grade group, ${ }^{3,4}$ although there are 
typically exceptions to the average. Athletes and students who need higher amounts of nutrients to fulfill daily needs could focus on consuming food throughout the day. Schools with food-insecure students could ensure that governmental programs serving free and reduced foods to students are available throughout the day, such as the National School Breakfast Program, ${ }^{34}$ Child and Adult Care Food Program, ${ }^{35}$ Fresh Fruit and Vegetable Program, ${ }^{36}$ and Afterschool Snack Program. ${ }^{37-39}$ Nutrition professionals could work with schools to understand requirements for accessing these governmental programs. Families and communities could focus on strategies to increase access to healthy foods in sufficient amounts throughout the day. The NSLP was not designed to hold the sole responsibility for fulfilling complete nutrient requirements for students during the entire day.

At the same time, other factors such as taste, variety, cultural/ethnic appropriateness, and visual appeal need to be considered to ensure that students will continue to support the NSLP and eat school lunch. Soliciting assistance from nutrition educators, local food and nutrition students, or nontraditional community partners, such as chefs, ${ }^{40}$ may help to address these concerns. Quality and taste are major predictors for older students participating in the NSLP and in food consumption. ${ }^{41,42}$ Other attributes may include the appearance of the cafeteria and treatment by school nutrition staff. In particular, these partners could provide staff training in food preparation to promote palatability in addition to healthfulness through innovative cooking techniques.

The new legislation continues to allow taste testing, which may be particularly effective with elementaryage children, whose taste preferences may not be fully developed. ${ }^{15,43}$ Taste testing may be difficult for the SFA to organize and manage in addition to daily duties, so the nutrition educator, local food and nutrition students, or chefs may have a role in alleviating some of these tasks. In addition, to promote greater FV intake and to reduce food waste, taste tests should be offered along with encouragement by foodservice personnel, teachers, and parents.

Involving students in designing school-wide education and marketing campaigns that highlight the NSLP standards may aid all stakeholders in understanding the benefits of the new guidelines and counter some of the negative reactions. These activities may also lead to positive discussion about effective solutions that incorporate student preferences. Encouraging youth involvement in modest school cafeteria changes may encourage buy-in to the program and reduce food waste, which is a significant and costly concern. ${ }^{44}$

Getlinger et $\mathrm{al}^{45}$ found that food waste is reduced when elementary students engage in recess before lunch. Other simple strategies, aligned with the Smarter Lunchrooms initiative, ${ }^{46}$ aim to nudge students into making healthier choices. These behavioral economics principles target increasing convenience, attractiveness, and normativeness. ${ }^{4-49}$ Simple strategies for achieving these principles include placing fresh fruit next to the cash register, changing the traffic flow in a cafeteria, using descriptive names appealing to youth, and promoting fruits and vegetables as a norm. The new NSLP regulations do not provide funds to cover education outside of competitive grants; creating lunchrooms that nudge students into making healthy choices may be a cost-effective strategy for SFAs without educational resources.

\section{RECOMMENDATIONS FOR RESEARCH AND EVALUATION}

The NSLP currently presents an environment and program that is ripe to conduct research studies to evaluate the ramifications of a far-reaching national policy such as the NSLP guidelines. Implementation and practice also overlap with research because evaluation of the NSLP should occur at all levels. First and foremost, will the new NSLP guidelines improve overall dietary quality and reduce childhood obesity? There is first the need to better understand whether healthier foods in the lunchroom affect short-term and long-term eating habits at school and in other food en- vironments. Researchers have evaluated eating habits and various nutritional outcomes in the school lunchroom; yet, more specificity is needed to determine the dietary quality of the foods consumed and foods wasted. ${ }^{50,51}$ In addition, as stated above, it may be warranted to invest in exploring whether providing more appealing, good-tasting, yet healthy meals diversify the NSLP participation and decrease health disparities in the lunchroom. Characterizing students via survey or intercept interviews in conjunction with plate waste studies may determine who is affected the most by the changes in the NSLP. This methodology could be used to assess health disparities for students at higher risk for obesity and food insecurity (eg, racial/ethnic minorities, low-income) or for different dietary requirements (eg, athletes or culturally appropriate food needs).

Ultimately, the new NSLP guidelines aim to improve the dietary habits of children while in school, and to have a spillover effect to other food environments by teaching students healthful eating habits and developing taste preferences. Understanding how the new NSLP guidelines improve the diet and reduce obesity is a question that requires sizeable commitments of time and money. Answers to these questions may be found in longitudinal or cross-sectional data sets that examine the new NSLP participants over time or compare the new NSLP participants with former NSLP participants. How school food policies affect dietary habits in other food environments (eg, home, community) may be difficult to capture; therefore, qualitative research with students, parents, and school personnel may help illuminate some of the key issues.

Beyond dietary intake, there are several food system issues to research and evaluate, including the effects of decreasing or diverting food waste and the economic impact of encouraging local foods in the cafeteria. Opportunities for examining the food supply also exist, such as the effect of the guidelines on food product reformulation and procurement policies and procedures. Researchers should focus on developing consistent, sensitive, and psychometrically sound measurement tools to measure 
outcomes on the NSLP standards in the realm of food systems, a burgeoning area of research. ${ }^{52-54}$ The role and feasibility that farm to school programs have under these new NSLP guidelines have yet to be determined.

To maximize the effect new school lunch guidelines have on the dietary intake and nutrition education of children, researchers could test different strategies that schools implement to meet the standards and even assess the impact of allowing flexibility in food offerings and calorie limits to meet school demands. Evaluating the ideal balance of guidelines and flexibility across various types of schools (size, location, sociodemographics of students, etc) in terms of the dietary behaviors of children could potentially fine-tune these guidelines.

Furthermore, interventions that educate parents, teachers, and foodservice personnel about the NSLP standards may help increase knowledge about the effect that nutrition education has on policy support. Creating buy-in for these new policies is important to have the intended impact during implementation and in the future. Finally, researchers should also measure the impact that implementation of SBP requirements has on the NSLP and overall consumption patterns of children.

With these opportunities, challenges, and questions, it is vital that policy makers, researchers, and practitioners work together to assess the implementation of the NSLP, to promote policies and strategies that positively affect student health and the future of our nation.

\section{REFERENCES}

1. National School Lunch Program fact sheet. US Department of Agriculture, Food and Nutrition Service. http:// www.fns.usda.gov/cnd/lunch/About Lunch/NSLPFactSheet.pdf. Accessed July 5, 2013.

2. Briefel RR, Wilson A, Gleason PM. Consumption of low-nutrient, energy-dense foods and beverages at school, home, and other locations among School Lunch participants and nonparticipants. J Am Diet Assoc. 2009; 109:S79-S90.
3. Healthy Hunger-Free Kids Act of 2010. US Department of Agriculture, Food and Nutrition Service. http://www .fns.usda.gov/cnd/governance/legislation /cnr_2010.htm. Accessed July 9, 2013.

4. US Department of Agriculture and US Department of Health and Human Services. Dietary Guidelines for Americans, 2010. 7th ed. Washington (DC): US Dept of Agriculture and US Dept of Health and Human Services; 2010.

5. Nutrition Standards in the National School Lunch and School Breakfast Programs: final rule. US Department of Agriculture. http://www.gpo.gov/ fdsys/pkg/FR-2012-01-26/html/20121010.htm. Published January 26, 2012. 77 Federal Registrar 17. Accessed July 5, 2013.

6. Healthy Hunger-Free Kids Act 2010, Public Law 111-296. 111th US Congress. www.gpo.gov/fdsys/pkg/PLAW111 publ296/pdf/PLA W-111 pub1296 .pdf. Published December 13, 2010. 124 STAT. 3183. Accessed July 5, 2013.

7. King S, Huelskamp T. The Hill Blog: "Let's Move" law is flawed. "No Hungry Kids Act" will fix it. http://thehill .com/blogs/congress-blog/education/ 258835-lets-move-law-is-flawed-nohungry-kids-act-will-fix-it. Accessed July 5, 2013.

8. National School Lunch Program: School Food Service Account Revenue Amendments Related to the Healthy, Hunger-Free Kids Act of 2010; Approval of Information Collection Request. US Department of Agriculture. https://www.federalregister.gov/articles/ 2012/04/02/2012-7762/national-schoollunch-program-school-food-service-ac count-revenue-amendments-related-tothe-healthy. Published April 2, 2012. 77 Federal Registrar 19525. Accessed July 5, 2013.

9. Nutrition standards for school meals. US Department of Agriculture, Food and Nutrition Service. http:// www.fns.usda.gov/cnd/governance/ legislation/nutritionstandards.htm. Accessed July 5, 2013.

10. Subchapter B-general regulations and policies - food distribution. US Department of Agriculture, Food and Nutrition Service. http://www .fns.usda.gov/fdd/regs/final/7cfr250 07donatedfoods.pdf. Accessed July 5, 2013.

11. Fact sheet: calories in school meals. US Department of Agriculture, Food and Nutrition Service. http://www.fns. usda.gov/cnd/governance/legislation/
HHFK Afactsheet-calories.pdf. Accessed July 5, 2013.

12. Nicklas T, Baranowski T, Cullen K, Berenson G. Eating patterns, dietary quality and obesity. $J$ Am Coll Nutr. 2001;20:599-608.

13. Anderson P, Butcher K. Childhood obesity: trends and potential causes. The Future of Children. 2006;16:19-45.

14. Guenther P, Dodd K, Reedy J, KrebsSmith S. Most Americans eat much less than recommended amounts of fruits and vegetables. J Am Diet Assoc. 2006;106:1371-1379.

15. Birch L, Savage JS, Ventura A. Influences on the development of children's eating behaviours: from infancy to adolescence. Can J Dietetic Pract Res. 2007;68:S1-S4, S6.

16. Food groups. US Department of Agriculture. http://www.choosemyplate. gov/food-groups/. Accessed July 5, 2013.

17. FNS guidance to school food authorities: flexibility in the meat/meat alternate and grain maximums for school year 2012-2013. US Department of Agriculture, Food and Nutrition Service. http://www.fns.usda.gov/cnd/ governance/Policy-Memos/2013/SP112013os.pdf. Accessed July 5, 2013.

18. National School Lunch Program and School Breakfast Program: nutrition standards for all foods sold in school as required by the Healthy, Hunger-Free Kids Act of 2010. US Department of Agriculture, Food and Nutrition Service. http://www.fns.usda.gov/cga/ 020113-snacks.pdf. Accessed July 5, 2013

19. Carlsson-Kanyama A, Gonzalez AD. Potential contributors of food consumption patterns to climate change. Am J Clin Nutr. 2009;89:1705S-1709S.

20. Young LR, Nestle M. The contribution of expanding portion sizes to the US obesity epidemic. Am J Publ Health. 2002;92:246-249.

21. Yon B, Johnson R, Stickle T. School children's consumption of lowercalorie flavored milk: a plate waste study. J Acad Nutr Diet. 2012;112: 132-136.

22. Ascherio A, Willett WC. Health effects of trans fatty acids. Am J Publ Health. 1997;66:1006S-1010S.

23. Patel A, Chandran K, Hampton KE, et al. Observations of drinking water access in school food service areas before implementation of federal and state school water policy, California, 2011. Prev Chronic Dis. 2012;9:E121. 
24. Hoeven J, Pryor M, Conrad K, et al. Letter to the US Secretary of Agriculture. http://www.hagstromreport.com/ assets/2012/2012_1120_JohnsonSchLunch .pdf. Accessed July 5, 2013.

25. Kline J, Noem K, Roe DP. Letter to Comptroller General of the United States. http://edworkforce.house.gov/ uploadedfiles/10-31-12_-_jpk_et_al_ttr_ to_gao_re_school_lunch.pdf. Committee on Education and the Workforce. Accessed July 5, 2013.

26. Kasperowicz, P. The Hill Blog: GOP bill would repeal Agriculture Department calorie caps on school lunches. http://thehill.com/blogs/floor-action/ house/249849-rep-king-pushes-torepeal-usdas-calorie-cap-at-schoollunch. Accessed July 5, 2013.

27. Gunderson G. The National School Lunch Program background and development. http://www.fns.usda.gov/cnd/ lunch/AboutLunch/ProgramHistory .htm. US Dept of Agriculture, Food and Nutrition Service. Accessed July 5, 2013.

28. Ogden CL, Carroll MD, Kit BK, Flegal KM. Prevalence of obesity and trends in body mass index among US children and adolescents. JAMA. 2012; 307:483-490.

29. Buzby J, Guthrie J. Plate waste in school nutrition programs. 2002. US Dept of Agriculture, Economic Research Service. http://naldc.nal.usda.gov/ download/48204/PDF. Accessed July 5, 2013.

30. Spruitj-Metz D. Etiology, treatment, and prevention of obesity in childhood adolescence: a decade in review. J Res on Adolesc. 2011;21:129-152.

31. Li J, O'Connell AA. Obesity, highcalorie food intake, and academic achievement trends among US school children. J Educ Res. 2012;105:391-403.

32. Mobley C, Stadler D, Staten M, et al. Effect of nutrition changes on foods selected by students in a middle school-based diabetes prevention intervention program: the HEALTHY Experience. J SchHealth. 2012;82:82-90.

33. Johnston Y, Denniston R, Morgan M, Bordeau M. Rock on Café: achieving sustainable systems changes in school lunch programs. Health Promot Pract. 2009;10:100S-108S.

34. School Breakfast Program. US Department of Agriculture, Food and Nutrition Service. http://www.fns.usda .gov/cnd/breakfast/. Accessed July 5, 2013.

35. Child and Adult Care Food Program. US Department of Agriculture, Food and Nutrition Service. http://www .fns.usda.gov/cnd/care/. Accessed July 5, 2013.

36. Fresh Fruit and Vegetable Program. US Department of Agriculture, Food and Nutrition Service. http://www.fns .usda.gov/cnd/ffvp/. Accessed July 5, 2013.

37. Afterschool snacks. US Department of Agriculture, Food and Nutrition Service. http://www.fns.usda.gov/cnd/ afterschool/. Accessed July 5, 2013.

38. Pearson N, Biddle SJ, Gorely T. Family correlates of breakfast consumption among children and adolescents: a systematic review. Appetite. 2009;52:1-7.

39. Bartfield J, Myoung K, Ryu JH, Ahn H-M. The School Breakfast Program: participation and impacts. http://naldc.nal.usda.gov/download/ 35895/PDF. US Dept of Agriculture. Accessed July 5, 2013.

40. Cohen JF, Smit LA, Parker E, et al. Long-term impact of a chef on school lunch consumption: findings from a 2-year pilot study in Boston middle schools. J Acad Nutr Diet. 2012;112: 927-933.

41. Meyer MK, Conklin MT. Variables affecting high school students' perceptions of school foodservice. J Am Diet Assoc. 1998;98:1424-1431.

42. Meyer MK. Top predictors of middle/ junior high school students' satisfaction with school food service and nutrition programs. J Am Diet Assoc. 2000;100: 100-103.

43. Birch LL, McPhee L, Shoba BC, Pirok E, Steinberg L. What kind of exposure reduces children's food neophobia? Looking vs. tasting. Appetite. 1987; 9:171-178.

44. Cohen JF, Richardson S, Austin SB, Economos CD, Rimm EB. School lunch waste among middle school students: nutrients consumed and costs. Am J Prev Med. 2013;44:114-121.

45. Getlinger MJ, Laughlin VT, Bell E, Akre C, Arjmandi BH. Food waste is reduced when elementary-school children have recess before lunch. J Am Diet Assoc. 1996;96:906-908.

46. Smarter lunchrooms. US Department of Agriculture, Food and Nutrition Service. http://healthymeals.nal. usda.gov/healthierus-school-challengeresources/smarter-lunchrooms. Accessed July 5, 2013.

47. Just DR, Wansink B. Smarter lunchrooms: using behavioral economics to improve meal selection. Choices. 2009; 24.

48. AS Hanks, DR Just, Wansink B. Smarter lunchrooms: libertarian paternalism can address new school lunchroom guidelines and childhood obesity. smarterlunchrooms.org/sites/default/files/ slm-jped-with-tables_12-20-12.pdf. Accessed July 5, 2013.

49. Wansink B, Just DR, Payne CR, Klinger MZ. Attractive names sustain increased vegetable intake in schools. Prev Med. 2012;55:330-332.

50. Reger C, O'Neil CE, Nicklas TA, Myers L, Berenson GS. Plate waste of school lunches served to children in a low-socioeconomic elementary school in south Louisiana. School Foodservice Research Review. 1996;20:3-19.

51. Martin CK, Thomson JL, LeBlanc MM, et al. Children in school cafeterias select foods containing more saturated fat and energy than the Institute of Medicine recommendations. J Nutr. 2010;140: 1653-1660.

52. Vallianatos M, Gottlieb R, Haase MA. Farm-to-school-strategies for urban health, combating sprawl, and establishing a community food systems approach. J Plan Educ Res. 2004;23: 414-423.

53. Feenstra G. Creating space for sustainable food systems: lessons from the field. Agr Hum Values. 2002;19:99-106.

54. Joshi A. Do farm-to-school programs make a difference? Findings and future research needs. J Hunger Environ Nutr. 2008;3:229-246. 